\title{
Valores do Terapeuta na Clínica Analítico-Comportamental ${ }^{1,2}$
}

\author{
João Paulo Watrin ${ }^{3}$ \\ Silvia Canaan \\ Universidade Federal do Pará
}

\begin{abstract}
RESUMO - Desde os anos 1950, tem se constatado que, em alguma medida, os valores do terapeuta se fazem presentes na psicoterapia, podendo, inclusive, influenciar os valores dos clientes. Embora apresente uma concepção de valores diferente das tradicionais, a terapia analítico-comportamental não é uma exceção. Este trabalho busca esclarecer como os valores do terapeuta podem se manifestar na clínica analítico-comportamental, sejam esses valores pessoais ou compartilhados com alguma cultura (e.g., sociedade em geral, Psicologia, Análise do Comportamento). Para tanto, mostra-se como o conceito de valor tem sido abordado na Análise do Comportamento e o que possibilita a manifestação dos valores do terapeuta na clínica analítico-comportamental. Por fim, discutem-se brevemente algumas implicações do tema para a prática clínica.
\end{abstract}

Palavras-chave: psicologia clínica, análise do comportamento, terapia analítico-comportamental, valores, ética

\section{Therapists' Values in Behavior-Analytic Therapy}

\begin{abstract}
Since the 1950s, it has been argued that, to some extent, therapists do not remain value-free in psychotherapy and may even influence clients' values. Behavior-analytic therapy is no exception to this rule, even though its concept of values differs from traditional views. This work demonstrates how therapists can reveal their values during behavior-analytic therapy, whether these values are personal or shared with a particular culture (e.g., society as a whole, psychology, behavior analysis). To this purpose, it reviews how values have been conceptualized in behavior analysis and discusses what makes it possible for therapists to disclose their values during behavior-analytic therapy. At the end, some implications of this issue for clinical practice are briefly discussed.
\end{abstract}

Keywords: clinical psychology, behavior analysis, behavior-analytic therapy, values, ethics

Na Psicologia Clínica, o papel dos valores do terapeuta tem despertado grande interesse desde os anos 1950. Já naquela época, Rosenthal (1955) acreditava ser possível que "o terapeuta comunique seus valores para o paciente de várias maneiras, sutilmente e sem intenção, ainda que tentando evitar fazer isso" (p. 436). Meehl (1959), por sua vez, considerava que os clientes "também têm um terceiro ouvido" (p. 256), capaz de identificar quando o terapeuta transmite valores pessoais. Desde então, diversos trabalhos sobre esse tema têm concordado que o terapeuta manifesta valores no processo psicoterápico, podendo, inclusive, influenciar os valores dos clientes (e.g., Kelly, 1990; Tjeltveit, 1986; Weisskopf-Joelson, 1980).

Nesse contexto, é bastante improvável que a clínica analítico-comportamental seja uma exceção. De fato, a Análise do Comportamento diverge das concepções tradicionais de valores, na medida em que ela os define como um fenômeno estritamente comportamental (e.g., Abib, 2001; Baum, 2006; Bonow \& Follette, 2009; Dittrich \& Abib, 2004; Hayes, Strosahl, \& Wilson, 2012; Leigland, 2005; Plumb, Stewart, Dahl, \& Lundgren, 2009; Skinner, 1953/1965, 1971, 1974; Tsai, Kohlenberg, Bolling, \& Terry, 2009; Wilson \& DuFrene, 2009). No entanto, se valores são um fenômeno comportamental e se conduzir uma terapia

1 Este trabalho reproduz parte do Trabalho de Conclusão de Curso do primeiro autor, orientado pela segunda autora e defendido na Universidade Federal do Pará em 2013

2 Os autores agradecem as críticas e sugestões de Aécio Borba, Cézar Quaresma e Rosângela Darwich às primeiras versões deste trabalho

3 Endereço para correspondência: Travessa Vileta, 688/409, Belém, PA, Brasil. CEP: 66.087-422.E-mail: jpwatrin@yahoo.com.br exige que o terapeuta se comporte, é perfeitamente possível que os valores do terapeuta analítico-comportamental se manifestem durante o processo psicoterápico. Tal como qualquer outro indivíduo, o terapeuta age a partir de uma história comportamental única, da qual fazem parte valores pessoais. Ao mesmo tempo, ele é parte de uma história cultural, estando exposto aos valores de diferentes culturas. Sendo assim, esse profissional pode vir a reproduzir na clínica tanto valores pessoais quanto valores culturais.

Por outro lado, esse assunto ainda é pouco discutido na literatura analítico-comportamental. Mesmo nos trabalhos que aludem ao tema, as discussões sobre os valores do cliente costumam sobrepujar as poucas menções aos valores do terapeuta (ver, e.g., Bonow \& Folette, 2009; Hayes et al., 2012; Leigland, 2005; Plumb et al., 2009; Wilson \& DuFrene, 2009; ver, porém, Vandenberghe, 2008). Além disso, para usar as palavras de Marçal (2005), "não se sabe, na prática, até que ponto os terapeutas têm o hábito de se questionar acerca de onde querem chegar na terapia ou por que escolheram determinados caminhos" (p. 243). Com isso, ficam em aberto questões sobre os interesses em jogo na terapia e sobre a própria função social da clínica da Análise do Comportamento (a esse respeito, ver também Bogo \& Laurenti, 2012; Dittrich \& Abib, 2004; Holland, 1978).

Esse quadro pode se dever à carência de trabalhos que sensibilizem os analistas do comportamento para a própria possibilidade de esses valores se manifestarem na clínica e repercutirem sobre o processo psicoterápico. Em uma tentativa de contribuir para esse debate, o presente artigo discute como é possível que os valores do terapeuta se manifestem na clínica analítico-comportamental, sejam esses 
valores pessoais ou compartilhados com alguma cultura (e.g., sociedade em geral, Psicologia, Análise do Comportamento). Para tanto, esta discussão se dividirá em duas seções. A primeira apresenta uma breve revisão do conceito de valor na literatura da análise do comportamento. Já a segunda seção parte de uma concepção analítico-comportamental de valores (Bonow \& Folette, 2009) para discutir o tema dos valores do terapeuta. Nesse sentido, esta seção aborda os determinantes dos valores do terapeuta para, em seguida, esclarecer o processo de manifestação deles na clínica. Por fim, argumenta-se que a terapia analítico-comportamental não está imune aos valores do terapeuta e se discutem brevemente algumas implicações dessa questão para a prática clínica.

\section{A Noção de Valores na Análise do Comportamento}

De um modo geral, valores fazem referência àquilo que é julgado como aceitável ou como inaceitável por um indivíduo ou por um grupo. São, portanto, definidos pela diferença entre o desejável e o indesejável, entre o "bom" e o "mau", entre o "certo" e o "errado". Ainda que com variações, essa concepção de valores tem sido adotada tanto no senso comum quanto na psicologia em geral (e.g., Rokeach, 1973; ver ainda Kelly, 1990). Tomada nesse sentido amplo, ela não é muito diferente da visão de muitos analistas do comportamento. Não por acaso, Baum (2006) reconhece que "os analistas comportamentais abordam questões relativas a valores, focalizando o que as pessoas fazem e dizem sobre coisas e atividades que são chamadas boas e más ou certas e erradas" (p. 253).

No entanto, a divergência começa quando a análise do comportamento concebe os valores como um fenômeno de natureza comportamental (e.g., Abib, 2001; Baum, 2006; Bonow \& Follette, 2009; Dittrich \& Abib, 2004; Hayes et al., 2012; Leigland, 2005; Plumb et al., 2009; Skinner, 1953/1965, 1971, 1974; Tsai et al., 2009; Wilson \& DuFrene, 2009). Com isso, os analistas do comportamento buscam abordar valores em termos de relações entre um indivíduo e seu ambiente, evitando as tradicionais referências a entidades mentais ou à "essência" de um indivíduo. Ainda assim, eles parecem divergir ao identificar os componentes do conceito de valor, isto é, a que aspectos das relações comportamentais o termo "valor" se refere.

\section{Valores na Perspectiva Skinneriana}

$\mathrm{Na}$ perspectiva skinneriana, o conceito de valor é geralmente associado às consequências do comportamento (e.g., Skinner, 1953/1965, 1971, 1974, 1981). Embora tratando apenas de consequências imediatas, Skinner (1971) chega mesmo a afirmar que "fazer um juízo de valor chamando alguma coisa de boa ou de ruim é classificá-la em termos de seus efeitos reforçadores" (p. 105). Nesse contexto, "as coisas boas são reforçadores positivos" (p. 103), isto é, estímulos consequentes que aumentam a probabilidade de o comportamento que os produziu ocorrer de novo. Por outro lado, as coisas ruins "são todas reforçadores negativos, e nós somos reforçados quando fugimos delas ou as evitamos" ( $p$. 104). Com isso, Skinner (1971) identifica as coisas ruins com o que se chama de estímulo aversivo, isto é, um estímulo consequente que, ao menos temporariamente, reduz a probabilidade de ocorrência da resposta que o produziu e cuja remoção reforça respostas de fuga e de esquiva (cf. Catania, 1998). É nesses sentidos, portanto, que as consequências podem ser tomadas como objetos de valor (ver, porém, a ideia skinneriana de sobrevivência das culturas como um valor mantido a longo prazo em Abib, 2001; Dittrich \& Abib, 2004; Ruiz \& Roche, 2007).

Além disso, o próprio comportamento do indivíduo pode vir a ser chamado de "bom" ou de "ruim", de "certo" ou de "errado". Essa classificação surge, sobretudo, no contexto de controle pelo grupo, em que "o comportamento do indivíduo é geralmente chamado de bom ou de correto na medida em que ele reforça outros membros do grupo e de ruim ou de errado na medida em que ele é aversivo" (Skinner, 1953/1965, p. 324; ver ainda Skinner, 1971, 1974, 1981). A partir daí, as ocorrências do comportamento considerado correto seriam reforçadas pelo grupo, ao passo que as ocorrências do errado seriam punidas, embora "as práticas correntes do grupo possam não ser completamente consistentes com essas definições" (Skinner, 1953/1965, p. 324).

Assim, na perspectiva skinneriana, um juízo de valor pode se referir tanto ao comportamento quanto às consequências desse comportamento. Por outro lado, é preciso considerar que o juízo de valor em si é um comportamento verbal (e.g., Skinner, 1953/1965, 1957, 1971, 1974; ver também Baum, 2006). Chamar um ato ou um objeto de "bom" ou de "ruim", de "certo" ou de "errado", é uma resposta verbal do falante que pode ser mantida ou enfraquecida pelas consequências fornecidas pelos ouvintes (Skinner, 1957). Como cada indivíduo possui uma história de reforçamento diferente, o que é "bom" para um indivíduo pode não ser "bom" para outro (Skinner, 1971). Do mesmo modo, o que o indivíduo considera "bom" ou "ruim" não é necessariamente o que o grupo chama de "bom" ou de "ruim" (ver ainda Skinner, 1981). Além disso, esses rótulos podem servir ao ouvinte como um estímulo antecedente verbal que indica as relações entre respostas e consequências, na medida em que as "boas" ações são geralmente reforçadas e as "más", punidas (Skinner, 1974). Dizer que uma ação é "boa" ou "má" é, portanto, indicar ao ouvinte as prováveis consequências do comportamento "bom" ou "ruim". Esses estímulos verbais constituem as regras, e o comportamento governado por elas é geralmente associado à questão dos valores (a esse respeito, ver Baum, 2006, Skinner, 1953/1965, 1969, 1971, 1974).

Dessa forma, a concepção skinneriana enfatiza o papel das consequências na determinação dos valores de um indivíduo ou mesmo de um grupo e estabelece uma distinção entre juízos de valor (componentes verbais) e objetos de valor (componentes não necessariamente verbais). É por envolver comportamentos observáveis que essa perspectiva toma os valores como mais um fato a ser explicado, abandonando a tradicional diferença ontológica entre fatos e valores (Leigland, 2005; Ruiz \& Roche, 2007). 


\section{Outras Concepções de Valores na Análise do Comportamento}

O conceito skinneriano de valor, por outro lado, não foi o único desenvolvido na Análise do Comportamento. Com efeito, há autores que aparentemente aderiram à perspectiva skinneriana (e.g., Abib, 2001; Baum, 2006; Dittrich \& Abib, 2004; Tsai et al., 2009). Ainda assim, novas definições foram criadas a partir de conceitos analítico-comportamentais. Uma delas é a encontrada na literatura da Terapia de Aceitação e Compromisso (Acceptance and Commitment Therapy, ACT), um modelo clínico fundamentado na análise do comportamento e na Teoria dos Quadros Relacionais (Hayes et al., 2012). Por estar embasada na Teoria dos Quadros Relacionais, a ACT parte do princípio de que algumas funções psicológicas são estabelecidas por padrões de responder relacional arbitrário, sem necessidade de condicionamento prévio ou direto (ver Hayes, Barnes-Holmes, \& Roche, 2001). Com isso, podem emergir redes de relações entre estímulos arbitrários, permitindo que estímulos relacionados entre si controlem uma mesma resposta. Essa perspectiva tornou possível a concepção da ACT de valores enquanto "motivação" verbalmente estabelecida para o agir, isto é, enquanto estímulos verbais que alteram a efetividade de um reforçador ou de um punidor (Hayes et al., 2012; Plumb et al., 2009, Wilson \& DuFrene, 2009). Em outras palavras, a ACT define o agir baseado em valores como uma espécie de comportamento governado por regras (cf. Hayes, Gifford,\& Hayes, 1998). Assim, quando, por exemplo, alguém diz a si próprio que acredita no "patriotismo" enquanto valor, as consequências das ações descritas como "patrióticas" podem vir a adquirir uma função reforçadora para o ouvinte. Isso acontece porque o estímulo "patriotismo" ocupa um papel central em uma rede da qual fazem parte outros estímulos hierarquicamente relacionados a ele, desde estímulos abstratos (e.g., "patriótico", "soberania nacional") até outros mais concretos (e.g., "ausência de estrangeiros no país"). No entanto, para que um determinado estímulo verbal seja um valor, ele deve ser livremente escolhido no sentido de que não deve envolver controle aversivo - isto é, por punição ou por reforçamento negativo. Não pode ser atingido nem realizado, mas tão somente abstraído ou ativamente construído a partir dos padrões comportamentais a ele relacionados. Dessa forma, a noção de valores da ACT enfatiza o papel dos componentes verbais, ainda que reconheça a relação destes com componentes não verbais.

Uma definição similar, porém mais ampla que a da ACT, é a proposta por Leigland (2005). Esse autor parte da ideia skinneriana de consequência como valor para associá-la ao conceito de operação estabelecedora, isto é, de operações que alteram a efetividade de uma consequência como reforçadora ou como punidora (cf. Catania, 1998; Michael, 1982). Para Leigland (2005), portanto, as operações estabelecedoras são as variáveis das quais os valores (i.e., consequências) são uma função, e não os valores em si. Como muitos valores surgem em interações verbais complexas, esse autor recorre à mesma concepção de regras utilizada na definição da $\mathrm{ACT}$, já que essas regras seriam uma variante verbal das operações estabelecedoras. No entanto, ao contrário da ACT, Leigland (2005) não só preserva o conceito de consequência como valor, mas também considera todos os tipos de operações estabelecedoras como determinantes dos valores - desde as incondicionadas (e.g., privação, saciação) até os processos verbais complexos.

Há ainda uma definição mais abrangente proposta por Bonow e Follette (2009), a qual será adotada neste trabalho por integrar todas as anteriores. Nessa concepção, valores são definidos em termos de três componentes. O primeiro deles é a ação de valor (valuing), que diz respeito aos comportamentos recorrentes que um indivíduo apresenta, independentemente do que ele relata sobre esses comportamentos. Engajar-se em uma atividade e não em outra seria, portanto, um indicativo do que o indivíduo valoriza. O segundo componente, por seu turno, são os chamados valores funcionais (functional values), que se referem às consequências que mantêm um comportamento e que podem ser afetadas por operações estabelecedoras. Assim, podem ser tomados como valores funcionais os estímulos consequentes que, historicamente, têm controlado o comportamento de uma pessoa (e.g., dinheiro, elogios). Já o terceiro componente são os valores declarados (statements of values), que dizem respeito a dois tipos de comportamentos verbais sobre valores. O primeiro refere-se ao ato de qualificar ações de valor e valores funcionais. São, portanto, os juízos de valor sobre comportamentos e consequências. Já o segundo tipo referese à formulação de regras que: (a) descrevem relações entre ações de valor e valores funcionais; ou (b) modificam a efetividade de uma consequência. Por seu papel no controle do comportamento, essas regras seriam as prescrições propriamente ditas. Assim, na definição de Bonow e Follette (2009), não há diferença de ênfase entre os aspectos verbal (valores declarados) e não necessariamente verbal (ações de valor e valores funcionais). Os três componentes estão intimamente relacionados e mudanças em um podem acarretar mudanças nos demais.

De um modo geral, verifica-se que, apesar das divergências, diversos autores da Análise do Comportamento concordam que valores são um fenômeno comportamental que envolve tanto componentes verbais quanto não verbais. Ressaltese, porém, que a abrangência das definições analíticocomportamentais de valores é, a um só tempo, um mérito e uma fraqueza. O caráter estritamente funcional dessas definições as torna amplas o suficiente para abarcar diversos tipos de valores. No entanto, elas chegam a ser tão amplas que falham em diferenciar valores de meras preferências ou mesmo de quaisquer outros comportamentos e talvez devessem ser complementadas por descrições topográficas - tal como se verifica em muitos códigos morais ou mesmo legais (e.g., Conselho Federal de Psicologia, CFP, 2005; American Psychological Association, APA, 2010). Ainda assim, a análise dessas limitações está fora do escopo deste trabalho.

\section{Valores do Terapeuta Analítico-Comportamental}

Se valores são um fenômeno comportamental e se conduzir uma terapia exige que o terapeuta se comporte, é razoável afirmar que a terapia analítico-comportamental não está imune aos valores desse profissional. Esta seção 
discute o que torna possível a manifestação dos valores do terapeuta na clínica da Análise do Comportamento. Para tanto, abordam-se os determinantes desses valores para que se possa, em seguida, explicar o processo de manifestação deles na clínica.

\section{Determinantes dos Valores do Terapeuta Analítico- Comportamental}

A partir do momento em que valores são tomados como comportamentos, explicar os valores do terapeuta é olhar para a sua história comportamental. O que o terapeuta faz (ações de valor), quais as consequências que mantêm o seu comportamento (valores funcionais) e o que ele relata sobre comportamentos e consequências (valores declarados) são questões que podem ser respondidas pela história de contato do terapeuta com diversos ambientes. É, portanto, a história do terapeuta que possibilita tanto a construção dos valores desse profissional quanto a manifestação deles na terapia.

Como cada terapeuta possui uma história e um repertório únicos, não há como dizer de antemão quais valores são compartilhados por todos os terapeutas. No entanto, é possível supor possíveis pontos em comum em suas histórias para se discutir os determinantes dos valores desses profissionais. Nesse contexto, podem se considerar dois níveis de análise interdependentes: a história do terapeuta enquanto indivíduo (história individual do terapeuta) e a história do terapeuta enquanto membro de diferentes culturas (história cultural do terapeuta). Esses níveis correspondem, aproximadamente, aos níveis ontogenético e cultural do modelo selecionista de Skinner (1981; ver ainda Leigland, 2005; Skinner, 1971, 1974). Deve-se ressaltar, no entanto, que valores também podem ser influenciados por fatores filogenéticos, isto é, pela história evolutiva da espécie (Baum, 2006; Bonow \& Folette, 2009; Skinner, 1971). Afinal, se as consequências podem ser tomadas como valores (ou, pelo menos, como parte deles), elas têm, em última análise, uma origem filogenética, uma vez que elas podem se constituir como - ou derivar de - estímulos reforçadores ou aversivos incondicionados.

\section{História individual do terapeuta}

Tal como qualquer outro indivíduo, o terapeuta possui uma história comportamental única, ao longo da qual se constrói o seu repertório particular de valores. É essa história que mostra como suas ações de valor, seus valores funcionais e seus valores declarados se estabeleceram no seu repertório e/ou adquiriram suas funções ao longo do tempo. Nesse sentido, os valores do terapeuta são produto do contato desse indivíduo com diversos ambientes de sua vida - desde os mais imediatos (e.g., familiares, amigos) até as culturas mais amplas das quais ele faz parte (e.g., profissão, sociedade em geral). Isso implica também considerar a experiência clínica desse profissional, uma vez que "geralmente o terapeuta é também reforçado pelo seu sucesso em aliviar o sofrimento de seus pacientes" (Skinner, 1953/1965, p. 382; ver também Skinner, 1971).

Sendo assim, pode-se dizer que os valores mais pessoais do terapeuta podem ser encontrados em sua história individual (cf. Skinner, 1971, 1974). Além disso, é essa história que pode esclarecer: (a) se existe correspondência entre o que o terapeuta diz (valores declarados) e faz (ações de valor e valores funcionais) em relação a valores (cf. Bonow-Follette, 2009); (b) em que medida o comportamento dele é governado por regras (cf. Hayes et al., 1998); e (c) até que ponto ele adere aos valores de uma cultura, reproduzindo as práticas ou seguindo as regras nela presentes (cf. Baum, 2006). Portanto, do ponto de vista individual, o termo valor refere-se a padrões comportamentais característicos do terapeuta. Esses padrões são construídos ao longo de uma história muito particular e envolvem componentes verbais (valores declarados) e não necessariamente verbais (ações de valor e valores funcionais), bem como os processos comportamentais a eles relacionados (e.g., correspondência entre dizer e fazer).

\section{História cultural do terapeuta}

Por outro lado, é preciso reconhecer que o terapeuta analítico-comportamental é também membro de diferentes culturas. Cada cultura, por sua vez, possui práticas e regras tradicionais, que podem ser consideradas valores culturais (ver também Baum, 2006; Skinner, 1953/1965; 1971, 1974, 1981). Sendo assim, é razoável supor que os valores do terapeuta sejam influenciados pelos valores da cultura, ou seja, os comportamentos do terapeuta podem vir a reproduzir práticas e regras comuns em um determinado grupo. A história cultural do terapeuta diz respeito, portanto, aos seus valores compartilhados com uma ou mais comunidades. No entanto, nem todos os terapeutas aderem necessariamente aos mesmos valores em uma dada cultura, uma vez que a história individual determina até que ponto cada terapeuta reproduzirá ou não os valores (i.e. prática e regras) de um determinado grupo.

Ainda assim, existem aquelas culturas com as quais o terapeuta analítico-comportamental necessariamente entra em contato. Como indivíduo, ele é parte da sociedade em que vive. Como profissional - e, quando é o caso, como pesquisador -, ele é também membro da comunidade da Psicologia e, em um nível mais restrito, da Análise do Comportamento. Sociedade, Psicologia e Análise do Comportamento são, portanto, algumas das mais prováveis fontes de valores culturais para o terapeuta analíticocomportamental.

Sociedade em geral. O terapeuta é membro de uma sociedade e não está, portanto, imune aos valores nela presentes. Com isso, esse profissional está invariavelmente exposto à forma como essa sociedade reforça ou pune determinados comportamentos, pois essa consequenciação é uma maneira de o grupo exercer controle sobre o indivíduo. Via de regra, isso se reflete em classificações como "certo" e "errado", "bom" e "mau", "legal" e "ilegal", "pecaminoso" e "virtuoso" ou até mesmo "normal" e "patológico" (ver, e.g., Skinner, 1953/1965, 1971, 1974). Esses conceitos costumam aparecer informalmente na forma de juízos de valor sobre comportamentos ou consequências. Quando esses juízos são formalizados como normas, mandamentos ou imposições morais, eles geralmente tomam a forma de regras que descrevem a relação tradicional entre comportamentos e consequências naquela sociedade (Baum, 2006; ver ainda Skinner, 1971). Nesse contexto, o terapeuta pode ou não agir de acordo com práticas e regras comuns na sociedade 
em que ele vive, quer ele se dê conta, quer não. É a história individual que vai indicar a probabilidade de isso acontecer no processo psicoterápico.

Comunidade científica e profissional da Psicologia. Ainda que alguns analistas do comportamento busquem afirmar sua independência em relação aos psicólogos (e.g., Fraley \& Vargas, 1986), é necessária a formação em Psicologia para exercer a profissão de psicoterapeuta no Brasil (Ministério do Trabalho e Emprego, 2010). Com isso, é razoável supor que a comunidade científica e profissional de psicólogos seja uma fonte de valores para o terapeuta analítico-comportamental. Ao longo de sua formação em Psicologia, o futuro terapeuta entra em contato tanto com professores quanto com a literatura da área. Pode também vir a participar de eventos e associações científicos e profissionais, bem como pode vir a desenvolver práticas de pesquisa e/ou de estágio supervisionado. Nesses contextos, o futuro terapeuta analítico-comportamental está exposto a práticas e regras comuns na comunidade da Psicologia e pode ser reforçado a reproduzi-las em seu comportamento. Além disso, a partir do momento em que passa a exercer a profissão, o terapeuta é regido pelo código de ética do psicólogo (CFP, 2005; ver também APA, 2010), que estabelece uma série de normas que regulam o comportamento profissional. Essas regras incluem, por exemplo, a necessidade de se respeitar o sigilo (CFP, 2005, Art. $9^{\circ}$ ) ou mesmo os valores dos clientes, uma vez que o psicólogo é proibido de "induzir [o cliente] a convicções políticas, filosóficas, morais, ideológicas, religiosas, de orientação sexual ou a qualquer tipo de preconceito, quando do exercício de suas funções profissionais" (CFP, 2005, Art. $2^{\circ}$, item [b], p. 9). O descumprimento dessas normas implica punições que podem vir a ameaçar a própria possibilidade de exercício da profissão de terapeuta.

Comunidade científica e profissional da Análise do Comportamento. Para se tornar um terapeuta analíticocomportamental, é evidente que um psicólogo precisa, antes, entrar em contato com a comunidade científica e profissional da Análise do Comportamento. Esse contato pode se dar pelos mesmos meios utilizados durante a formação em Psicologia, isto é, pela literatura da área, por professores adeptos da perspectiva, práticas de pesquisa, entre outros. No entanto, a adesão à perspectiva analítico-comportamental implica o uso dos sistemas conceitual e filosófico da área, bem como o contato com o seu arsenal técnico e metodológico (ver, e.g., Baer, Wolf \& Risley, 1968; Hayes, 1978). Reproduzir as práticas e regras comuns nessas dimensões seria, de certa forma, aderir aos valores da Análise do Comportamento. Embora nem todos esses valores sejam igualmente compartilhados entre os membros da área, pode-se dizer, ainda assim, que, pela sua centralidade na perspectiva da abordagem, alguns valores podem ser mais amplamente difundidos ou partilhados do que outros. É o caso, por exemplo, da postura antimentalista - a tentativa de evitar a explicação do comportamento por processos ou entidades mentais (e.g., Skinner, 1974). Outros valores dizem respeito especificamente à prática clínica, como a audiência não punitiva, segundo a qual o terapeuta deve evitar fazer uso da punição durante o processo terapêutico (Skinner, 1953/1965). Todos esses valores acabam por se fazer presentes nas práticas do terapeuta da Análise do Comportamento, na medida em que eles próprios caracterizam a clínica analíticocomportamental.

\section{A Manifestação dos Valores do Terapeuta na Clínica}

São, portanto, as histórias individual e cultural que determinarão os valores que cada terapeuta poderá manifestar na clínica. Embora não seja possível especificar de antemão que valores são esses, a própria interação entre terapeuta e cliente já é condição suficiente para evocar ações de valor, valores funcionais ou valores declarados.

$\mathrm{Na}$ verdade, esses valores podem se fazer presentes antes mesmo de a terapia começar, com a aceitação ou recusa de um potencial cliente. Um terapeuta pode, por exemplo, se recusar a atender uma pessoa porque o perfil desse possível cliente é incompatível com os valores desse profissional. Já em um encontro inicial, o cliente pode relatar comportamentos que o terapeuta aprendeu a julgar como "ruins" (e.g., estupro, pedofilia, violência doméstica), tendo o terapeuta aprendido também a evitar as pessoas que praticam esses comportamentos. Com isso, esse profissional pode alegar uma incapacidade pessoal para se responsabilizar pelo caso, uma vez que o terapeuta deve "assumir responsabilidades profissionais somente por atividades para as quais esteja capacitado pessoal, teórica e tecnicamente [itálico acrescentado]" (CFP, 2005, Art. 1º, item [b], p. 8).

Quando a terapia se inicia, os valores do terapeuta podem se manifestar virtualmente em qualquer prática característica da profissão. O próprio direcionamento que o terapeuta dá ao diálogo já pode revelar alguns de seus valores. A escolha dos tópicos a serem abordados, a forma como colocações e perguntas são feitas e a ênfase dada a certos aspectos da fala do cliente são apenas algumas dimensões da fala do terapeuta que manifestam os valores desse profissional. Um terapeuta pode, por exemplo, privilegiar a investigação de um assunto, como uma área de vida ou um evento específico. Nesse caso, as colocações e perguntas sobre o assunto investigado já configuram ações de valor do terapeuta, indicando que esse profissional valoriza investigar especificamente esse aspecto da história do cliente. Já as falas do cliente evocadas pelo terapeuta acabam por servir como valores funcionais para o comportamento investigativo desse profissional. Nesse contexto, é possível que os valores mais visíveis na investigação do terapeuta analítico-comportamental sejam os da própria Análise do Comportamento, como a ênfase no papel das consequências e a valorização do controle por reforçamento positivo (cf. Skinner, 1953/1965, 1971, 1974). A ênfase nas consequências, por exemplo, pode transparecer em casos em que o cliente não costuma relatar as consequências que ele próprio gera ao agir, casos em que o terapeuta procura identificá-las. Já a valorização do reforçamento positivo pode se manifestar quando o terapeuta busca investigar as possíveis fontes de reforçamento na vida do cliente. Com isso, fica claro como os valores da análise do comportamento podem transparecer no comportamento investigativo do terapeuta, mas nada impede que esse comportamento reproduza também valores pessoais ou mesmo os valores compartilhados com alguma outra cultura. 
Esses são casos de verbalizações do terapeuta que manifestam valores desse profissional, mas que não são propriamente verbalizações sobre os valores do terapeuta. Trata-se, portanto, de uma manifestação implícita de valores, ou melhor, de ações de valor e valores funcionais. Por outro lado, o terapeuta também pode manifestar explicitamente alguns de seus valores declarados. Tsai et al. (2009) indicam três possibilidades de esse tipo de manifestação acontecer. Em primeiro lugar, o terapeuta pode verbalizar os chamados "fatos terapêuticos", relações entre respostas e consequências identificadas pela Ciência e que podem vir a serviço do cliente. É o caso, por exemplo, do terapeuta que alerta o cliente para o fato de que uma vida social mais ativa pode aumentar a resistência à depressão. Em segundo lugar, o terapeuta pode manifestar a chamada "ética terapêutica", falas que descrevem os padrões éticos da profissão e que podem contribuir para o bem-estar do cliente. Pode ser o caso, por exemplo, da garantia de sigilo, com a qual o terapeuta indica que a privacidade do cliente será respeitada. As verbalizações de fatos terapêuticos e da ética terapêutica estão, portanto, relacionadas a valores culturais presentes na profissão e são esperadas pela maioria dos clientes. No entanto, uma terceira possibilidade é que o terapeuta manifeste seus próprios valores pessoais ao longo da terapia, o que, segundo Tsai et al. (2009), poderia não ser esperado pelo cliente.

Assim, a forma como o terapeuta direciona o diálogo clínico pode manifestar, mais ou menos explicitamente, tanto os seus valores pessoais quanto aqueles valores compartilhados com uma dada cultura. Nesse contexto, convergências e divergências de valores entre terapeuta $e$ cliente podem repercutir em pontos fundamentais da terapia.

O que o cliente chama de "problema", por exemplo, pode não corresponder ao que o terapeuta considera problemático e levar os dois a conceberem diferentes estratégias de enfrentamento. Essa divergência pode, muito bem, decorrer do fato de que o terapeuta apresenta valores diferentes dos do cliente (ver também Bogo \& Laurenti, 2012). Se o cliente vive em uma sociedade que valoriza a crença em causas internas, ele pode atribuir o problema somente a sentimentos indesejáveis e pedir ajuda ao terapeuta para se livrar deles (Kohlenberg, Tsai, \& Dougher, 1993). Já um terapeuta que adere aos valores da Análise do Comportamento pode, por sua vez, atribuir o problema às relações de controle existentes entre o contexto em que o cliente vive (i.e., ambiente) e os sentimentos do cliente (i.e., comportamentos). A partir daí, o terapeuta poderia, nos moldes da ACT, trabalhar com o cliente a aceitação desses sentimentos indesejáveis em vez de buscar modificá-los, o que seria um primeiro passo para que o cliente começasse a buscar experiências que deem sentido à sua própria vida (ver, e.g., Hayes et al., 2012). Portanto, a avaliação do problema não está livre dos valores do terapeuta, o que poderia repercutir diretamente sobre os objetivos da terapia.

Por outro lado, também a avaliação da melhora de cada cliente está longe da neutralidade. As avaliações de progresso clínico que ocorrem ao longo da terapia podem, certamente, ser tomadas como um juízo de valor do terapeuta. Esse julgamento pode, de fato, ser construído com o cliente. Nesse caso, o cliente pode ser solicitado a fazer ele próprio uma avaliação de seu percurso na terapia, enquanto o terapeuta busca complementar ou discutir o juízo que ele, enquanto profissional, faz do progresso do cliente. No entanto, a avaliação do terapeuta pode diferir significativamente do juízo do cliente, e o terapeuta pode optar por fazer uma avaliação unilateral (ver, e.g., Kelly, 1990). Como indicam Bonow e Follette (2009), essa diferença de julgamentos pode se dever à habilidade do terapeuta para identificar "sinais de melhora". No entanto, como afirmam os mesmos autores, é também possível que essa diferença decorra do fato de que, ao longo do processo terapêutico, o cliente passou ou não a apresentar um comportamento verbal que reproduz o comportamento verbal do terapeuta, incluindo os próprios valores desse profissional. Não por acaso, Kohlenberg e Tsai (2007) admitem que "toda forma de psicoterapia parece ensinar o cliente a dar explicações que são aceitáveis para o terapeuta [itálico acrescentado]” (p. 37), e a clínica analíticocomportamental não seria exceção.

E certo, portanto, que, nas práticas de qualquer terapeuta analítico-comportamental, estão implícitos valores sobre o que é "desejável" ou "indesejável", sobre o que traz ou reduz o bem-estar (cf. Ruiz \& Roche, 2007). No entanto, quando se fala em comportamentos "desejáveis" e "indesejáveis" na terapia, dificilmente se deixa claro quem determina o “desejável” e o "indesejável”. Em alguma medida, é possível que essa determinação seja negociada entre terapeuta e cliente. Por outro lado, a partir do momento em que essa questão é deixada nas entrelinhas da terapia, é possível que o desejável e o indesejável fiquem inconscientemente a cargo do terapeuta. Isso é particularmente visível em modelos como a Psicoterapia Analítico-Funcional (Functional Analytic Psychotherapy, FAP). Na FAP, há uma distinção clara entre os comportamentos clinicamente relevantes que expressam o problema (CRB1) e os que expressam a melhora (CRB2) do cliente, e a definição desses comportamentos fica geralmente a cargo do terapeuta (Kohlenberg \& Tsai, 2007; ver ainda Vandenberghe, 2008).

Assim, ao possuir esse poder de definir o desejável e o indesejável, um terapeuta pode, inadvertidamente, buscar reproduzir certos valores pessoais ou mesmo valores culturais no comportamento do cliente. Se, por exemplo, o terapeuta adere a valores de cunho racista ou sexista, ele pode acabar reforçando naturalmente os comportamentos do cliente que são compatíveis com uma cultura racista ou sexista, de forma mais ou menos sutil e ainda que não se dê conta disso (Kohlenberg \& Tsai, 2007). Também o inverso pode acontecer quando o terapeuta acaba punindo os comportamentos do cliente que não condizem com os valores desse profissional.

Essa possibilidade de os valores do terapeuta influenciarem os do cliente é o aspecto da terapia em que os valores desse profissional mais podem se fazer evidentes. Tratase de uma das questões mais debatidas na literatura sobre valores na terapia, sendo chamada de "convergência" ou, pejorativamente, de "conversão de valores" (e.g., Kelly, 1990; Meehl, 1959; Rosenthal, 1955; Tjeltveit, 1986; Weisskopf-Joelson, 1980). Especificamente na Análise do Comportamento, essa questão se torna mais explícita quando os próprios valores do cliente são o foco da terapia, uma questão que tem sido discutida, sobretudo, na literatura da 
ACT (e.g., Hayes et al., 2012; Plumb et al., 2009, Wilson \& DuFrene, 2009; ver ainda Bonow \& Follette, 2009; Tsai et al., 2009). É certo que a ética profissional proíbe, de forma mais ou menos explícita, que os valores do cliente sofram qualquer tipo de influência, exceto nos casos em que esses valores possam trazer prejuízos para o próprio cliente ou para terceiros (ver, e.g., APA, 2010; CFP, 2005). No entanto, diversos autores da análise do comportamento parecem concordar que, ao longo da terapia, as mudanças no comportamento do cliente acarretam uma mudança de valores (e.g., Bonow \& Follette, 2009; Hayes et al., 2012; Leigland, 2005; Plumb et al., 2009; Tsai et al., 2009; Wilson $\&$ DuFrene, 2009). Por vezes, os próprios valores do cliente estão entre as causas do problema que ele relata, fazendo com que esses valores precisem ser repensados. Essa postura, no entanto, não significa que deva haver imposição de valores por parte do terapeuta (Bonow \& Follette, 2009; Plumb et al., 2009). Como afirmam Bonow e Follette (2009), não é porque um terapeuta consegue viver bem com alguns valores que estes valores se tornam apropriados para um determinado cliente. Ainda assim, a partir do instante em que os valores do cliente são o foco da terapia, nada impede que eventuais mudanças ocorram na direção dos valores do terapeuta, a despeito das prescrições da literatura ou da ética profissional, quer o terapeuta se dê conta disso, quer não.

Dessa forma, a manifestação dos valores do terapeuta é garantida pela própria estrutura de uma terapia. Pela análise aqui apresentada, é possível que, ao longo da terapia, o terapeuta expresse tanto valores pessoais quanto culturais, de forma implícita ou explícita. Em todo caso, não há como garantir que eles venham necessariamente a serviço do cliente. O que se pode pensar, de uma forma geral, é que, em uma terapia, "o papel dos valores parece variar de acordo com os valores do paciente, os valores do terapeuta e os problemas tratados em uma relação terapêutica particular" (Kelly, 1990, p. 184).

\section{Considerações Finais}

A discussão aqui apresentada argumentou que a terapia analítico-comportamental não está imune aos valores do terapeuta, sejam esses valores pessoais ou compartilhados com alguma cultura (e.g., Análise do Comportamento, Psicologia, Sociedade em geral). No entanto, este trabalho não esgota as possibilidades de reflexão ou mesmo de investigação sobre o tema. Esta discussão constitui uma análise puramente formal, que não tem, portanto, como esclarecer o conteúdo axiológico de qualquer terapia analítico-comportamental em particular. Em outras palavras, esta discussão não tem como apontar quais valores o terapeuta efetivamente manifesta ao longo de uma terapia. Ao que tudo indica, os valores e a forma como eles se manifestam variam não só de profissional para profissional, mas variam também de acordo com a própria relação terapêutica estabelecida. Ao se manifestarem, eles transparecem mais no comportamento verbal do terapeuta, uma vez que a clínica da Análise do Comportamento é uma prática essencialmente verbal (Kohlenberg et al., 1993). No entanto, nada impede que esses valores transpareçam também no comportamento não verbal do terapeuta. Com isso, "a aparência e as roupas do terapeuta, bem como a aparência de seu consultório, comunicam valores. Até mesmo um reservado 'mhm' ou uma reflexão rogeriana poderiam, dependendo do momento, sugerir ao cliente o que o terapeuta vê como importante" (Weisskopf-Joelson, 1980, p. 462).

Em todo caso, o que fica claro é que a terapia analíticocomportamental está longe de ser uma prática neutra, livre de qualquer espécie de valores por parte do terapeuta. Se a clínica fosse neutra, não haveria espaço para terapias a serviço do terapeuta, para todas aquelas terapias que caminham não para uma mudança na vida do cliente, mas tão somente para a manutenção do cliente enquanto tal - isto é, como pagante do terapeuta (ver também Epling \& Woodward, 1976). Ainda assim, seria justo pensar que os valores desse profissional só são questionáveis no caso do "mau terapeuta"? Será que, graças à sua formação científica e profissional, o terapeuta "comum" estaria imunizado contra qualquer tipo de viés?

Só o fato de um cliente chegar à terapia em situação de sofrimento já estabelece um desequilíbrio de poder entre terapeuta e cliente. Esse desequilíbrio não é necessariamente ruim, mas permite que um mesmo profissional possa tanto ajudar quanto prejudicar um determinado cliente. $\mathrm{O}$ que vai acontecer exatamente dependerá da forma como o terapeuta reagirá ao cliente, ou melhor, do que controlará o comportamento do terapeuta (Kohlenberg \& Tsai, 2007; ver também Skinner, 1953/1965; 1974). É comum pensar que terapeutas estão sob o controle da "melhora" do cliente, muito embora, como já foi visto, a avaliação dessa melhora possa ser influenciada pelos valores desse profissional. Ainda assim, na relação terapêutica, o cliente pode se comportar de maneiras que reforçam o comportamento do terapeuta de explorar o próprio cliente. Kohlenberg e Tsai (2007) afirmam, por exemplo, que atitudes como a subserviência, admiração, masculinidade ou feminilidade do cliente podem funcionar como reforçadores e, portanto, como valores funcionais para o comportamento do terapeuta. Assim, se o terapeuta estiver sob o controle desses aspectos do comportamento do cliente, a ideia de que a terapia ajuda pode mascarar um processo que mantém o cliente a serviço do terapeuta em vez do contrário.

No entanto, a mera existência dessa possibilidade não significa que ela seja um fato em toda e qualquer relação terapêutica. A presença dos valores do terapeuta na clínica analítico-comportamental não significa que eles necessariamente enviesam a terapia de forma negativa. Ela significa sim que a figura do terapeuta deve ser levada em conta em toda e qualquer prática psicoterápica. O terapeuta é, invariavelmente, fruto de uma história. Ele fala e age de um determinado lugar, manifestando valores pessoais e culturais. Por isso mesmo, o conhecimento do cliente que se constrói ao longo de uma terapia não é construído independentemente do terapeuta (ver também Kohlenberg \& Tsai, 2007). O terapeuta e os seus respectivos valores são o contexto para que a análise funcional ocorra e devem, por isso mesmo, ser incluídos nela (Bolling, 2002; Vandenberghe, 2008). Para tanto, o terapeuta precisa, antes, desenvolver uma consciência de seus próprios valores. Deve aprender a discriminar quais são seus valores e quando eles se manifestam, bem como deve estar atento à possível incompatibilidade deles com os valores do cliente. Esse esforço do terapeuta pelo autoconhecimento 
é eticamente necessário e perfeitamente factível, sobretudo quando esse profissional pode contar com o auxílio da própria comunidade de terapeutas, seja na figura de um colega, de um supervisor ou mesmo de seu próprio terapeuta (Kohlenberg \& Tsai, 2007; ver também Banaco, 1993, 2001).

Sendo assim, se sempre existe a possibilidade de os valores do terapeuta se manifestarem, cabe ao próprio terapeuta buscar reconhecer quais valores ele coloca em jogo na relação terapêutica. Só assim ele poderá avaliar o impacto deles sobre o cliente e, se for o caso, redirecionar sua prática clínica. A reflexão sobre esse tema constitui, portanto, um espaço privilegiado para se repensar a própria prática dos terapeutas analítico-comportamentais. Essa reflexão exige um enfrentamento honesto da questão sobre os valores em jogo na relação terapêutica, um passo que já tem sido dado por alguns autores (e.g., Bolling, 2002; Bonow \& Folette, 2009; Tsai et al., 2009; Vandenberghe, 2008; ver ainda Ruiz \& Roche, 2007; Weisskopf-Joelson, 1980). Ao mesmo tempo, ela exige que se abandone a pretensão (ou mesmo ingenuidade) de se pensar o terapeuta ou a terapia como neutros ou imparciais. A discussão aqui apresentada buscou ser mais um passo em direção a essas exigências. De modo nenhum, ela pretende negar o valor da terapia em si, mas sim reconhecer que a pessoa do terapeuta e o mundo em que ele vive se fazem presentes nas práticas psicoterápicas.

\section{Referências}

Abib, J. A. D. (2001). Teoria moral de Skinner e desenvolvimento humano. Psicologia: Reflexão e Crítica, 14, 107-117.

American Psychological Association (2010). Ethical principles of psychologists and code of conduct - with the 2010 amendments. Washington, DC: American Psychological Association.

Baer, D. M., Wolf, M. M., \& Risley, T. R. (1968). Some current dimensions of applied behavior analysis. Journal of Applied Behavior Analysis, 1, 91-97.

Banaco, R. A. (1993). O impacto do atendimento sobre a pessoa do terapeuta. Temas em Psicologia, 2, 71-79.

Banaco, R. A. (2001). O impacto do atendimento sobre a pessoa do terapeuta 2: experiências de vida. In M. Delitti (Ed.), Sobre comportamento e cognição (2a ed., Vol. 2, pp. 169-176). Santo André, ESETec.

Baum, W. M. (2006). Compreender o behaviorismo: comportamento, cultura e evolução ( $2^{\mathrm{a}}$ ed., M. T. A. Silva, M. A. Matos, G. Y. Tomanari, \& E. Z. Tourinho, Trans.). Porto Alegre: Artmed.

Bogo, A. C., \& Laurenti, C. (2012). Análise do Comportamento e sociedade: implicações para uma ciência dos valores. Psicologia: Ciência e Profissão, 32, 956-971.

Bolling, M. Y. (2002). Research and representation: A conundrum for behavior analysts. Behavior and Social Issues, 12, 19-28.

Bonow, J. T., \& Follette, W. C. (2009). Beyond values clarification: Addressing client values in clinical behavior analysis. The Behavior Analyst, 32, 69-84.

Catania, A. C. (1998). Learning (4 $4^{\mathrm{a}}$ ed.). Upper Saddle River, Prentice-Hall.

Conselho Federal de Psicologia (2005). Código de ética profissional do psicólogo. Brasília: Conselho Federal de Psicologia.
Dittrich, A., \& Abib, J. A. D. (2004). O sistema ético skinneriano e consequências para a prática dos analistas do comportamento. Psicologia: Reflexão e Crítica, 17, 427-433.

Epling, W. F., \& Woodward, J. B. (1976). How to be a successful psychotherapist no matter what the effect on behavior: The Corn Soup Principle. Behaviour Research and Therapy, 14, 482-484.

Fraley, L. E., \& Vargas, E. A. (1986). Separate disciplines: The study of behavior and the study of the psyche. The Behavior Analyst, 9, 47-59.

Hayes, S. C. (1978). Theory and technology in Behavior Analysis. The Behavior Analyst, 1, 25-33.

Hayes, S. C., Barnes-Holmes, D., \& Roche, B. (Eds.). (2001). Relational frame theory: A post-Skinnerian account of human language and cognition. Nova York: Springer.

Hayes, S. C., Gifford, E. V., \& Hayes, G. J. (1998). Moral behavior and the development of verbal regulation.The Behavior Analyst, 21, 253-279.

Hayes, S. C., Strosahl, K. D., \& Wilson, K. G. (2012). Acceptance and commitment therapy: The process and practice of mindful change ( $2^{\mathrm{a}}$ ed.). Nova York: Guilford Press.

Holland, J. G. (1978). Behaviorism: Part of the problem or part of the solution? Journal of Applied Behavior Analysis, 11, 163-174.

Kelly, T. A. (1990). The role of values in psychotherapy: A critical review of process and outcome effects. Clinical Psychology Review, 10, 171-186.

Kohlenberg, R. J., \& Tsai, M. (2007). Functional analytic psychotherapy: Creating intense and curative therapeutic relationships. Nova York: Springer.

Kohlenberg, R. J., Tsai, M., \& Dougher, M. J. (1993). The dimensions of clinical behavior analysis. The Behavior Analyst, $16,271-282$.

Leigland, S. (2005).Variables of which values are a function.The Behavior Analyst, 28, 133-142.

Marçal, J. V. S. (2005). Estabelecendo objetivos na prática clínica: Quais caminhos seguir? Revista Brasileira de Terapia Comportamental e Cognitiva, 7, 231-245.

Meehl, P. E. (1959). Some technical and axiological problems in the therapeutic handling of religious and valuational material. Journal of Counseling Psychology, 6, 255-259.

Michael, J. (1982). Distinguishing between discriminative and motivational functions of stimuli. Journal of the Experimental Analysis of Behavior, 37, 149-155.

Ministério do Trabalho e Emprego. (2010). Classificação brasileira de ocupações: $C B O-2010$ (3 $3^{\mathrm{a}}$ ed., Livro 1). Brasília: Ministério do Trabalho e Emprego / Secretaria de Políticas Públicas de Emprego.

Plumb, J. C., Stewart, I., Dahl, J. A., \&Lundgren, T. (2009). In search of meaning: Values in modern clinical behavior analysis. The Behavior Analyst, 32, 85-103.

Rokeach, M. (1973). The nature of human values. Nova York: Free Press.

Rosenthal, D. (1955). Changes in some moral values following psychotherapy. Journal of Counseling Psychology, 6, 431-436.

Ruiz, M. R., \& Roche, B. (2007). Values and the scientific culture of behavior analysis.The Behavior Analyst, 30, 1-16.

Skinner, B. F. (1957). Verbal behavior. Englewood Cliffs: PrenticeHall.

Skinner, B. F. (1965). Science and human behavior. Nova York: Free Press. (Trabalho original publicado em 1953) 
Skinner, B. F. (1969). Contingencies of reinforcement: A theoretical analysis. Nova York: Appleton-Century-Crofts.

Skinner, B. F. (1971). Beyond freedom and dignity. Indianapolis: Hackett Publishing.

Skinner, B. F. (1974). About behaviorism. Nova York: Vintage Books.

Skinner, B. F. (1981). Selection by consequences. Science, 213, 501-504.
Tjeltveit, A. C. (1986). The ethics of value conversion in psychotherapy: Appropriate and inappropriate therapist influence on client values. Clinical Psychology Review, 6, 515-537.

Tsai, M., Kohlenberg, R. J., Bolling, M. Y., \& Terry, C. (2009). Values in therapy and Green FAP. In M. Tsai, J. R. Kohlenberg, J. W. Kanter, B. Kohlenberg, W. C. Follete, \& G. M. Callaghan (Eds.), A guide to functional analytic psychotherapy: Awareness, courage, love and behaviorism. (pp. 199-212). Nova York: Springer.

Vandenberghe, L. (2008). Culture-sensitive functional analytic psychotherapy. The Behavior Analyst, 31, 67-79.

Weisskopf-Joelson, E. (1980). Values: The enfant terrible of psychotherapy. Psychotherapy: Theory, Research and Practice, 17, 459-466.

Wilson, K.,\&DuFrene, T. (2009). Mindfulness for two: An acceptance and commitment therapy approach to mindfulness in psychotherapy. Oakland: New Harbinger., 